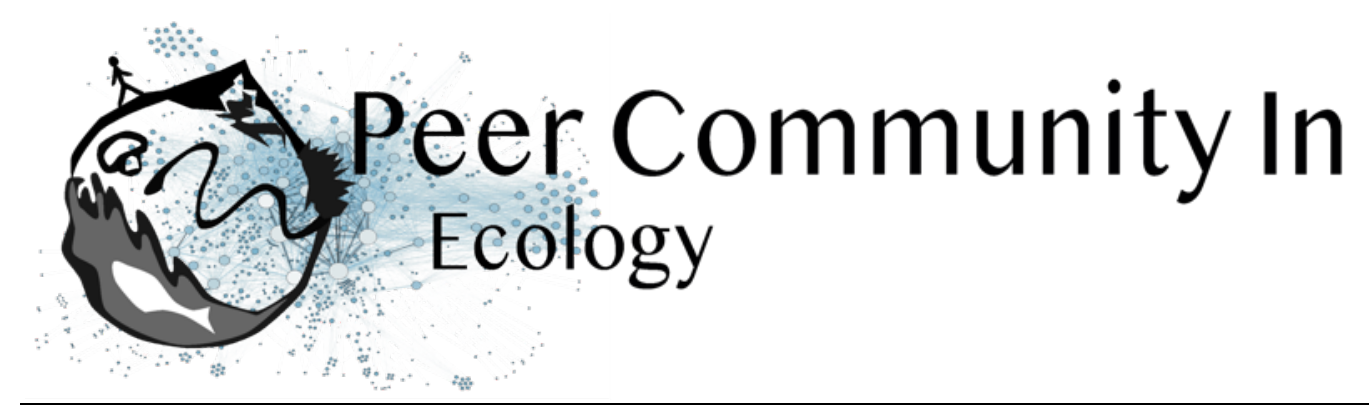

RESEARCH ARTICLE

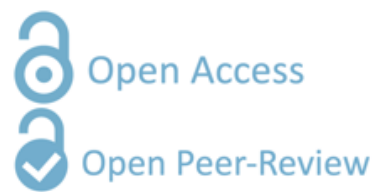

Cite as: Dittami SM, Arboleda E, Auguet J-C, et. al.. A community perspective on the concept of marine holobionts: current status, challenges, and future directions. Zendoo, peer-reviewed and recommended by PCI Ecology (2020), doi:10.5281/zenodo.3696771.

Posted: $5^{\text {th }}$ March 2020

Recommenders:

Sophie Arnaud-Haond and Corinne Vacher

Reviewers:

Aurélie Tasiemski and Sophie Arnaud-Haond

Correspondence: simon.dittami@sb-roscoff.fr catherine.leblanc@sb-roscoff.fr fabrice.not@sb-roscoff.fr

\section{A community perspective on the concept of marine holobionts: current status, challenges, and future directions}

The Holomarine working group ${ }^{*}$ Simon M. Dittami ${ }^{1}$, Enrique Arboleda ${ }^{2}$, Jean-Christophe Auguet ${ }^{3}$, Arite Bigalke ${ }^{4}$, Enora Briand ${ }^{5}$, Paco Cárdenas ${ }^{6}$, Ulisse Cardini ${ }^{7}$, Johan Decelle ${ }^{8}$, Aschwin $\mathrm{H}$. Engelen $^{9}$, Damien Eveillard ${ }^{10}$, Claire M.M. Gachon ${ }^{11}$, Sarah M. Griffiths $^{12}$, Tilmann Harder ${ }^{13}$, Ehsan Kayal ${ }^{2}$, Elena Kazamia ${ }^{14}$, Francois H. Lallier ${ }^{15}$, Mónica Medina ${ }^{16}$, Ezequiel M. Marzinelli ${ }^{17}$, Teresa Morganti ${ }^{18}$, Laura Núñez Pons ${ }^{19}$, Soizic Prado ${ }^{20}$, José Pintado Valverde ${ }^{21}$, Mahasweta Saha ${ }^{22}$, Marc-André Selosse ${ }^{23}$, Derek Skillings ${ }^{24}$, Willem Stock ${ }^{25}$, Shinichi Sunagawa ${ }^{26}$, Eve Toulza ${ }^{27}$, Alexey Vorobev $^{28}$, Catherine Leblanc ${ }^{1}$, and Fabrice Not ${ }^{15}$

* This working group gathers 31 scientists from ten different countries, with expertise covering different scientific disciplines including philosophy, evolution, computer sciences, marine biology, ecology, chemistry, and microbiology, who participated in a workshop on marine holobionts, organized at the Roscoff Biological Station in March 2018. Their aim was to exchange ideas regarding key concepts and opportunities in marine holobiont research, to start structuring the community, and to identify and tackle key challenges in the field.

1 Sorbonne Université, CNRS, Integrative Biology of Marine Models (LBI2M), Station Biologique de Roscoff, 29680 Roscoff, France

2 Sorbonne Université, CNRS, FR2424, Station Biologique de Roscoff, 29680 Roscoff, France

3 MARBEC, Université de Montpellier, CNRS, IFREMER, IRD, Montpellier, France

4 Institute for Inorganic and Analytical Chemistry, Bioorganic Analytics, FriedrichSchiller-Universität Jena, Lessingstrasse 8, D-07743 Jena, Germany

5 Ifremer, Laboratoire Phycotoxines, 44311 Nantes, France 


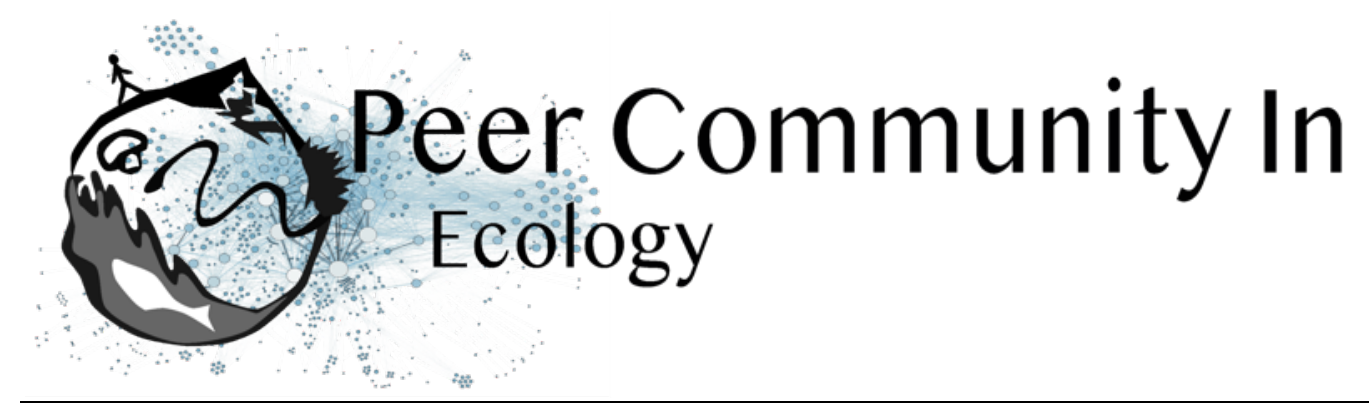

6 Pharmacognosy, Dept. of Medicinal Chemistry, Uppsala University, BMC Box 574, 75123 Uppsala, Sweden

7 Integrative Marine Ecology Dept., Stazione Zoologica Anton Dohrn, Napoli, Italy

8 Laboratoire de Physiologie Cellulaire et Végétale, Université Grenoble Alpes, CNRS, CEA, INRA; 38054, Grenoble Cedex 9, France

9 CCMAR, Universidade do Algarve, Campus de Gambelas, Faro, Portugal

10 Université de Nantes, CNRS, Laboratoire des Sciences Numériques de Nantes (LS2N), 44322 Nantes, France

11 Scottish Association for Marine Science, Scottish Marine Institute, PA37 1QA Oban, UK

12 School of Science and the Environment, Manchester Metropolitan University, Manchester, UK

13 University of Bremen, Leobener Strasse 6, 28359 Bremen, Germany

14 Institut de Biologie de l'ENS, 46 rue d'Ulm, 75005 Paris, France

15 Sorbonne Université, CNRS, Adaptation and Diversity in the Marine Environment, Station Biologique de Roscoff, 29680 Roscoff, France

16 Dept. of Biology, Pennsylvania State University, University Park PA 16801, USA

17 The University of Sydney, School of Life and Environmental Sciences, Sydney, NSW 2006, Australia; Singapore Centre for Environmental Life Sciences Engineering, Nanyang Technological University, Singapore; Sydney Institute of Marine Science, Mosman, NSW 2088, Australia

18 Max Planck Institute for Marine Microbiology, Celsiusstraße 1, 28359 Bremen, Germany

19 Section Biology and Evolution of Marine Organisms (BEOM), Stazione Zoologica Anton Dohrn (SZN), Villa Comunale, 80121, Napoli, Italy

20 Molecules of Communication and Adaptation of Microorganisms (UMR 7245), National Museum of Natural History, CNRS, 57 rue Cuvier, 75005 Paris, France

21 Instituto de Investigaciones Marinas (IIM-CSIC), Eduardo Cabello 6, 36208 Vigo, Galicia, Spain

22 Benthic Ecology, Helmholtz Center for Ocean Research, Düsternbrooker Weg 20, 24105 Kiel, Germany; Marine Ecology and Biodiversity, Plymouth Marine Laboratory, PL1 3DH Plymouth, UK.

23 Département Systématique et Evolution, Muséum national d'Histoire naturelle, UMR 7205 ISYEB, CP 50, 45 rue Buffon, Paris 75005, France; Faculty of Biology, University of Gdansk, ul. Wita Stwosza 59, 80- 308, Gdansk, Poland

24 Philosophy Dept., University of Pennsylvania, 249 S. 36th Street, Philadelphia PA 191046304, USA

25 Laboratory of Protistology \& Aquatic Ecology, Dept. of Biology, Ghent University, Krijgslaan 281-S8, 9000 Ghent, Belgium 


\section{a. 2 Peer Community In Ecology}

26 Dept. of Biology, Institute of Microbiology and Swiss Institute of Bioinformatics, ETH Zürich, Vladimir-Prelog-Weg 4, 8093 Zürich, Switzerland

27 Univ. Perpignan Via Domitia, IHPE UMR 5244, CNRS, IFREMER, Univ. Montpellier, 66000 Perpignan, France

28 CEA - Institut de Biologie François Jacob, Genoscope, 2 Rue Gaston Crémieux, 91057 Evry, France

This article has been peer-reviewed and recommended by Peer Community in Ecology

\section{ABSTRACT}

Host-microbe interactions play crucial roles in marine ecosystems. However, we still have very little understanding of the mechanisms that govern these relationships, the evolutionary processes that shape them, and their ecological consequences. The holobiont concept is a renewed paradigm in biology that can help to describe and understand these complex systems. It posits that a host and its associated microbiota, living together in a stable relationship, form a holobiont, and have to be studied together as a coherent biological and functional unit to understand its biology, ecology, and evolution. Here we discuss critical concepts and opportunities in marine holobiont research and identify key challenges in the field. We highlight the potential economic, sociological, and environmental impacts of the holobiont concept in marine biological, evolutionary, and environmental sciences. Given the connectivity and the unexplored biodiversity specific to marine ecosystems, a deeper understanding of such complex systems requires further technological and conceptual advances, e.g. the development of controlled experimental model systems for holobionts from all major lineages and the modeling of (info)chemical-mediated interactions between organisms. Here we propose that one significant challenge is to bridge cross-disciplinary research on tractable model systems in order to address key ecological and evolutionary questions. This first step is crucial to decipher the main drivers of the dynamics and evolution of holobionts and to account for the holobiont concept in applied areas, such as the conservation, management, and exploitation of marine ecosystems and resources. 


\section{Glossary*}

* If no other examples of the use of each term are cited below, the definition was based on the online version of the MerriamWebster dictionary (2019, https://www.merriam-webster.com/) or the Oxford dictionary (2020, https://www.lexico.com/)

Anna Karenina principle - a number of factors can cause a system to fail, but only a narrow range of parameters characterizes a working system; based on the first sentence of Leo Tolstoy's "Anna Karenina" (1878): "Happy families are all alike; every unhappy family is unhappy in its own way" (Zaneveld et al. 2017).

Aposymbiotic culture - a culture of a host or a symbiont without its main symbiotic partner(s) (e.g. Kelty and Cook 1976). In contrast to gnotobiotic cultures, aposymbiotic cultures are usually not germ-free.

Biological control (biocontrol) - methods for controlling diseases or pests by introducing or supporting natural enemies of the former (see e.g. Hoitink and Boehm 1999).

Biomonitoring - the use of living organisms as quantitative indicator for the health of an environment or ecosystem (Holt and Miller 2010).

Community assembly process - the processes that shape community composition in a given habitat, according to Nemergut et al. (2013) the four main forces relevant for community assembly are evolutionary diversification, dispersal, selection, and ecological drift.

Dysbiosis - microbial imbalance in a symbiotic community that affects the health of the host (Egan and Gardiner 2016).

Ecological process - the processes responsible for the functioning and dynamics of ecosystems including biogeochemical cycles, community assembly processes, interactions between organisms, and climatic processes (see e.g. Bennett et al. 2009).

Ecosystem services - any direct or indirect benefits that humans can draw from an ecosystem; they include provisioning services (e.g. food), regulating services (e.g. climate), cultural services (e.g. recreation), and supporting services (e.g. habitat formation) (Millennium Ecosystem Assessment Panel 2005).

Ectosymbiosis - a symbiotic relationship in which symbionts live on the surface of a host. This includes, for instance, algal biofilms or the skin microbiome (Nardon and Charles 2001).

Emergent property - a property of complex systems (e.g. holobionts), which arises from interactions between the components and that is not the sum of the component properties (see e.g. Theis 2018).

Endosymbiosis (sometimes also referred to more precisely as endocytobiosis; Nardon and Charles 2001) - a symbiotic relationship in which a symbiont lives inside the host cells; prominent examples are mitochondria, plastids/photosymbionts, or nitrogen fixing bacteria in plant root nodules. See also ectosymbioisis.

Gnotobiosis - the condition in which all organisms present in a culture can be controlled, i.e. germ-free (axenic) organisms or organisms with a controlled community of 
symbionts. Gnotobiotic individuals may be obtained e.g. by surgical removal from the mother (vertebrates) or by surface sterilization of seeds (plants) and subsequent handling in a sterile environment and possible inoculation with selected microbes (Hale et al. 1973; Williams 2014).

Holism - the theory that parts of a whole are in intimate interconnection, such that they cannot exist independently of the whole, or cannot be understood without reference to the whole, which is thus regarded as greater than the sum of its parts.

Holobiont - an ecological unit of different species living together in symbiosis. The term is frequently used for the unit of a host and its associated microbiota but can be extended to larger scales. Whether or to what extent holobionts are also a unit of evolution is still a matter of debate (Douglas and Werren 2016).

Hologenome - the combined genomes of the host and all members of its microbiota; Rosenberg et al. 2007a; Zilber-Rosenberg and Rosenberg 2008)

Horizontal transmission - acquisition of the associated microbiome from the environment (e.g. Myers and Rothman 1995; Roughgarden 2019, preprint).

Host - the largest or dominant partner in a holobiont.

Infochemical - a chemical compound, usually diffusible, that carries information on the environment, such as the presence of other organisms, and can be used to mediate inter- and intraspecific communication (Dicke and Sabelis 1988).

Microbial gardening - the act of frequently releasing growth-enhancing or inhibiting chemicals or metabolites that favor the development of a microbial community beneficial to the host (see e.g. Saha and Weinberger 2019).

Microbiome - the combined genetic information encoded by the microbiota; may also refer to the microbiota itself or the microbiota and its environment (see Marchesi and Ravel 2015).

Microbiota - all microorganisms present in a particular environment or associated with a particular host (see Marchesi and Ravel 2015).

Nested ecosystems - a view of ecosystems where each individual system, like a "Russian doll", can be decomposed into smaller systems and/or considered part of a larger system (Figure 2), all of which still qualify as ecosystems (e.g. McFall-Ngai et al. 2013).

Phagocytosis - a process by which a eukaryotic cell ingests other cells or solid particles, e.g. the uptake of bacteria by sponges (Leys et al. 2018).

Phycosphere - the physical envelope surrounding a phytoplankton cell; usually rich in organic matter (see Amin et al. 2012).

Phylosymbiosis - congruence in the phylogeny of different hosts and the composition of their associated microbiota (Brooks et al. 2016).

Rasputin effect - the phenomenon that commensals and mutualists can become parasitic in certain conditions (Overstreet and Lotz 2016); after the Russian monk Rasputin who became the confidant of the Tsar of Russia, but later helped bring down the Tsar's empire during the Russian revolution. 
Sponge loop - sponges efficiently recycle dissolved organic matter turning it into detritus that becomes food for other consumers (de Goeij et al. 2013).

Symbiont - an organism living in symbiosis; usually refers to the smaller/microbial partners living in mutualistic relationships (see also host), but also includes organisms in commensalistic and parasitic relationships.

Symbiosis - a close and lasting or recurrent (e.g. over generations) relationship between organisms living together; usually refers to mutualistic relationships, but also includes commensalism and parasitism.

Vertical transmission - acquisition of the associated microbiome by a new generation of hosts from the parents (as opposed to horizontal transmission; e.g. Roughgarden 2019, preprint).

\section{Marine holobionts from their origins to the present}

\section{The history of the holobiont concept}

Holism is a philosophical notion first proposed by Aristotle in the $4^{\text {th }}$ century BC. It states that systems should be studied in their entirety, with a focus on the interconnections between their various components rather than on the individual parts (Met. Z.17, 1041b11-33). Such systems have emergent properties that result from the behavior of a system that is 'larger than the sum of its parts'. However, a major shift away from holism occurred during the Age of "Enlightenment" when the dominant thought summarized as "dissection science" was to focus on the smallest component of a system as a means of understanding it.

The idea of holism started to regain popularity in biology when the endosymbiosis theory was first proposed by Mereschkowski (1905) and further developed by Wallin (1925). Still accepted today, this theory posits a single origin for eukaryotic cells through the symbiotic assimilation of prokaryotes to form first mitochondria and later plastids (the latter through several independent symbiotic events) via phagocytosis (reviewed in Archibald 2015). These ancestral and founding symbiotic events, which prompted the metabolic and cellular complexity of eukaryotic life, most likely occurred in the ocean (Martin et al. 2008).

Despite the general acceptance of the endosymbiosis theory, the term 'holobiont' did not immediately enter the scientific vernacular. It was coined by Lynn Margulis in 1990, who proposed that evolution has worked mainly through symbiosis-driven leaps that merged organisms into new forms, referred to as 'holobionts', and only secondarily 
through gradual mutational changes (Margulis and Fester 1991; O'Malley 2017). However, the concept was not widely used until it was co-opted by coral biologists over a decade later. Corals and dinoflagellate algae of the family Symbiodiniaceae are one of the most iconic examples of symbioses found in nature; most corals are incapable of long-term survival without the products of photosynthesis provided by their endosymbiotic algae. Rohwer et al. (2002) were the first to use the word "holobiont" to describe a unit of selection sensu Margulis (Rosenberg et al. 2007b) for corals, where the holobiont comprised the cnidarian polyp (host), algae of the family Symbiodiniaceae, various ectosymbionts (endolithic algae, prokaryotes, fungi, other unicellular eukaryotes), and viruses.

Although initially driven by studies of marine organisms, much of the research on the emerging properties and significance of holobionts has since been carried out in other fields of research: the microbiota of the rhizosphere of plants or the animal gut became predominant models and have led to an ongoing paradigm shift in agronomy and medical sciences (Bulgarelli et al. 2013; Shreiner et al. 2015; Faure et al. 2018). Holobionts occur in terrestrial and aquatic habitats alike, and several analogies between these ecosystems can be made. For example, in all of these habitats, interactions within and across holobionts such as induction of chemical defenses, nutrient acquisition, or biofilm formation are mediated by chemical cues and signals in the environment, dubbed infochemicals (Loh et al. 2002; Harder et al. 2012; Rolland et al. 2016; Saha et al. 2019). Nevertheless, we can identify two major differences between terrestrial and aquatic systems. First, the physicochemical properties of water result in higher chemical connectivity and signaling between macro- and micro-organisms in aquatic or moist environments. In marine ecosystems, carbon fluxes also appear to be swifter and trophic modes more flexible, leading to higher plasticity of functional interactions across holobionts (Mitra et al. 2013). Moreover, dispersal barriers are usually lower, allowing for faster microbial community shifts in marine holobionts (Kinlan and Gaines 2003; Martin-Platero et al. 2018). Secondly, phylogenetic diversity at broad taxonomic scales (i.e. supra-kingdom, kingdom and phylum levels), is higher in aquatic realms compared to land, with much of the aquatic diversity yet to be uncovered (de Vargas et al. 2015; Thompson et al. 2017), especially marine viruses (Middelboe and Brussaard 2017; Gregory et al. 2019). The recent discovery of such astonishing marine microbial diversity in parallel with the scarcity of marine holobiont research suggest a high potential for complex cross-lineage interactions yet to be explored in marine holobionts (Figure 1).

The boundaries of holobionts are usually delimited by a physical gradient, which corresponds to the area of local influence of the host, e.g. in unicellular algae the so-called phycosphere (Seymour et al. 2017). However, they may also be defined in a context- 

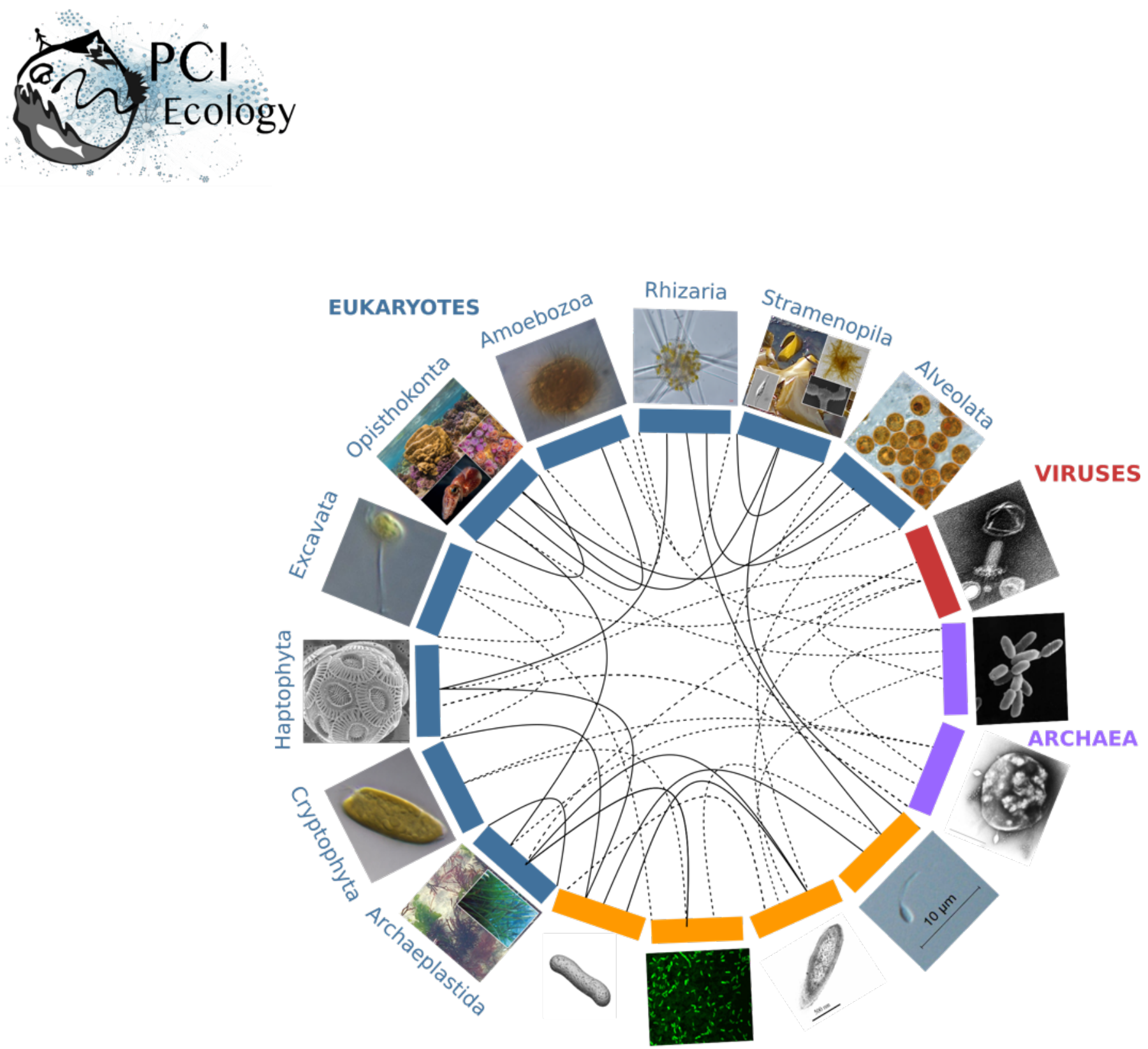

BACTERIA

Figure 1. Partners forming marine holobionts are widespread across the tree of life including all kingdoms (eukaryotes, bacteria, archaea, viruses), and represent a large diversity of potential models for exploring complex biotic interactions across lineages. Plain lines correspond to holobionts referred to in the present manuscript. Dashed lines are examples of potential interactions. Photo credits: Archaeplastida - C. Leblanc, U Cardini; Cryptophyta, Excavata, Amoebozoa - Roscoff Culture Collection; Stramenopila C. Leblanc, S. M. Dittami, H. KleinJan; Alveolata - A. M. Lewis; Rhizaria - F. Not; Haptophyta - A. R. Taylor; Opisthonkonta - C. Frazee, M. McFall-Ngai, W. Thomas, L. Thiault; Bacteria - E Nelson, L Sycuro, S. M. Dittami, S. Le Panse, Planktomania; Archaea - National Space Science Data Center, Xiaoyu Xiang; Viruses - M. B. Sullivan et al..

dependent way as a 'Russian Matryoshka doll', setting the boundaries of the holobiont depending on the interactions and biological functions that are being considered. Thus 


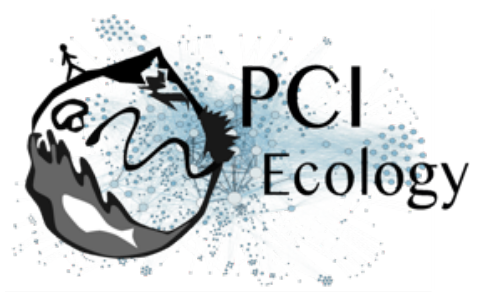

holobionts may encompass all levels of host-symbiont associations from intimate endosymbiosis with a high degree of co-evolution up to the community and ecosystem level; a concept referred to as "nested ecosystems" (Figure 2; McFall-Ngai et al. 2013; Pita et al. 2018).

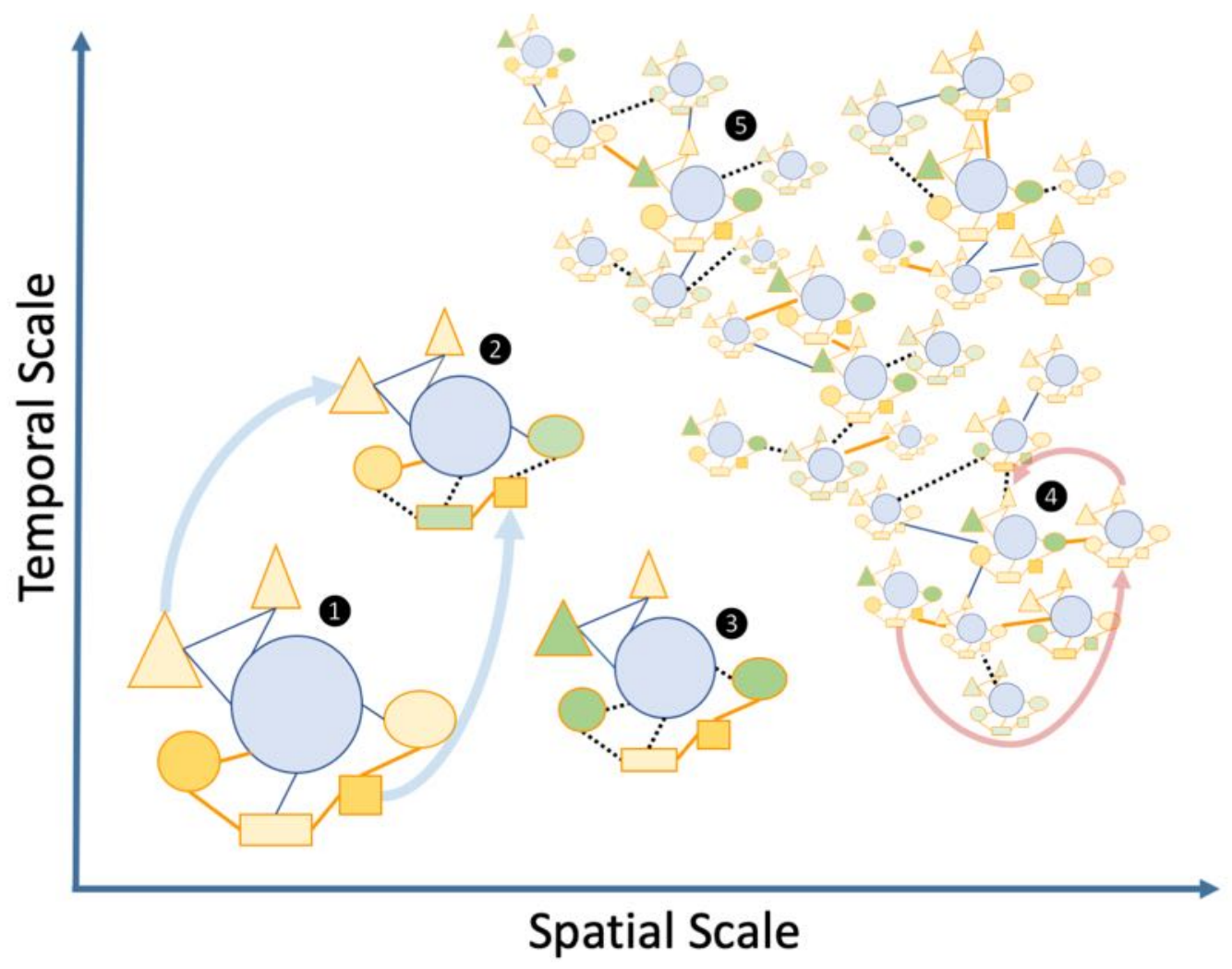

Figure 2. Schematic view of the "Russian Doll" complexity and dynamics of holobionts, according to diverse spatiotemporal scales. The host (blue circles), and associated microbes (all other shapes) including bacteria and eukaryotes that may be inside (i.e. endosymbiotic or outside the host, i.e. ectosymbiotic, are connected by either beneficial (solid orange lines), neutral (solid blue lines) or pathogenic (dashed black lines) interactions respectively. Changes from beneficial or neutral to pathogenic interactions are typical cases of dysbiosis. The different clusters can be illustrated by the following examples: 1, a model holobiont in a stable physiological condition (e.g. in controlled laboratory condition); 2 and 3, holobionts changing during their life cycle or submitted to stress conditions - examples of vertically transmitted microbes are indicated by light blue arrows; 4 and 5, marine holobionts in the context of global sampling campaigns or longterm time series - examples of horizontal transmission of microbes and holobionts are illustrated by pink arrows. 
Such a conceptual perspective raises fundamental questions not only regarding the interaction between the different components of holobionts and processes governing their dynamics, but also of the relevant units of selection and the role of co-evolution. For instance, plant and animal evolution involves new functions co-constructed by members of the holobiont or elimination of functions redundant among them (Selosse et al. 2014), and it is likely that these processes are also relevant in marine holobionts. Rosenberg et al. (2010) and Rosenberg and Zilber-Rosenberg (2018) argued that all animals and plants can be considered holobionts, and thus advocate the hologenome theory of evolution, suggesting that natural selection acts at the level of the holobiont and its hologenome. This interpretation of Margulis' definition of a 'holobiont' considerably broadened fundamental concepts in evolution and speciation and has not been free of criticism (Douglas and Werren 2016), especially when applied at the community or ecosystem level (Moran and Sloan 2015). More recently, it has been shown that species that interact indirectly with the host can also be important in shaping coevolution within mutualistic multi-partner assemblages (Guimarães et al. 2017). Thus, the holobiont concept and the underlying complexity of holobiont systems should be better defined and further considered when addressing evolutionary and ecological questions.

\section{Marine holobiont models}

Today, an increasing number of marine model organisms, both unicellular and multicellular, are being used in holobiont research (Figure 1), often with different emphasis and levels of experimental control, but altogether covering a large range of scientific topics. Here, we provide several illustrative examples of this diversity and some of the insights they have provided.

Environmental or "semi-controlled" models, i.e. holobiont systems in which microbiome composition is not or only partially controlled: radiolarians and foraminiferans (both heterotrophic protist dwellers harboring endosymbiotic microalgae) are emerging as ecological models for unicellular photosymbiosis due to their ubiquitous presence in the world's oceans (Decelle et al. 2015; Not et al. 2016). The siphonous green alga Bryopsis is an example of a model that harbors heterotrophic endosymbiotic bacteria, some of which exhibit patterns of co-evolution with their hosts (Hollants et al. 2013). The discovery of deep-sea hydrothermal vents revealed symbioses of animals with chemosynthetic bacteria that have later been found in many other marine ecosystems (Dubilier et al. 2008; Rubin-Blum et al. 2019) and frequently exhibit high levels of metabolic and taxonomic diversity (Duperron et al. 2008; Petersen et al. 2016; Ponnudurai et al. 2017). The 


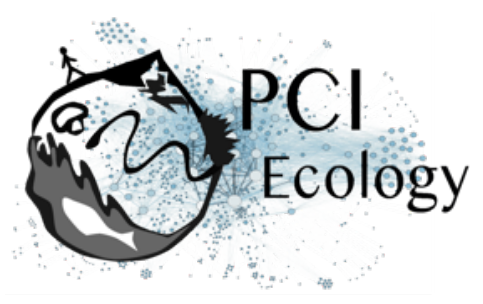

cosmopolitan haptophyte Emiliania huxleyi, promoted by associated bacteria (Seyedsayamdost et al. 2011; Segev et al. 2016), produces key intermediates in the carbon and sulfur biogeochemical cycles, making it an important model phytoplankton species.

Controlled bi- or trilateral associations: Only a few models, covering a small part of the overall marine biodiversity, are currently being cultivated ex-situ and can be used in fully controlled experiments, where they can be cultured aposymbiotically. The flatworm Symsagittifera (= Convoluta) roscoffensis (Arboleda et al. 2018), the sea anemone Exaiptasia (Baumgarten et al. 2015; Wolfowicz et al. 2016), the upside-down jellyfish Cassiopea (Ohdera et al. 2018), and their respective intracellular green and dinoflagellate algae have, in addition to corals, become models for fundamental research on evolution of metazoan-algal photosymbiosis. In particular, Exaiptasia has been used to explore photobiology disruption and restoration of cnidarian symbioses (Lehnert et al. 2012). The Vibrio-squid model provides insights into the effect of microbiota on animal development, circadian rhythms, and immune systems (McFall-Ngai 2014). The unicellular green alga Ostreococcus, an important marine primary producer, has been shown to exchange vitamins with specific associated bacteria (Cooper et al. 2019). The green macroalga Ulva mutabilis has enabled the exploration of bacteria-mediated growth and morphogenesis including the identification of original chemical interactions in the holobiont (Wichard 2015; Kessler et al. 2018). Although the culture conditions in these highly-controlled model systems differ from the natural environment, these systems are essential to gain elementary mechanistic understanding of the functioning, the roles, and the evolution of marine holobionts.

\section{The influence of marine holobionts on ecological processes}

Work on model systems has demonstrated that motile and macroscopic marine holobionts can act as dissemination vectors for geographically restricted microbial taxa. Pelagic mollusks or vertebrates are textbook examples of high dispersal capacity organisms (e.g. against currents and through stratified water layers). It has been estimated that fish and marine mammals may enhance the original dispersion rate of their microbiota by a factor of 200 to 200,000 (Troussellier et al. 2017) and marine birds may even act as bio-vectors across ecosystem boundaries (Bouchard Marmen et al. 2017). This host-driven dispersal of microbes can include non-native or invasive species as well as pathogens (Troussellier et al. 2017).

A related ecological function of holobionts is their potential to sustain rare species. Hosts provide an environment that favors the growth of specific microbial communities distinct from the surrounding environment (including rare microbes). They may, for 
instance, provide a nutrient-rich niche in the otherwise nutrient-poor surroundings (Smriga et al. 2010; Webster et al. 2010; Burke, Thomas, et al. 2011; Chiarello et al. 2018).

Lastly, biological processes regulated by microbes are important drivers of global biogeochemical cycles (Falkowski et al. 2008; Madsen 2011; Anantharaman et al. 2016). In the open ocean, it is estimated that symbioses with the cyanobacterium UCYN-A contribute $\sim 20 \%$ to total $\mathrm{N}_{2}$ fixation (Thompson et al. 2012; Martínez-Pérez et al. 2016). In benthic systems, sponges and corals may support entire ecosystems via their involvement in nutrient cycling thanks to their microbial partners (Raina et al. 2009; Fiore et al. 2010; Cardini et al. 2015; Pita et al. 2018), functioning as sinks and sources of nutrients. In particular the "sponge loop" recycles dissolved organic matter and makes it available to higher trophic levels in the form of detritus (de Goeij et al. 2013; Rix et al. 2017). In coastal sediments, bivalves hosting methanogenic archaea have been shown to increase the benthic methane efflux by a factor of up to eight, potentially accounting for $9.5 \%$ of total methane emissions from the Baltic Sea (Bonaglia et al. 2017). Such impressive metabolic versatility is accomplished because of the simultaneous occurrence of disparate biochemical machineries (e.g. aerobic and anaerobic pathways) in individual symbionts, providing new metabolic abilities to the holobiont, such as the synthesis of specific essential amino acids, photosynthesis, or chemosynthesis (Venn et al. 2008; Dubilier et al. 2008). Furthermore, the interaction between host and microbiota can potentially extend the metabolic capabilities of a holobiont in a way that augments its resilience to environmental changes (Berkelmans and van Oppen 2006; Gilbert et al. 2010; Dittami et al. 2016; Shapira 2016; Godoy et al. 2018), or allow it to cross biotope boundaries (e.g. Woyke 2006) and colonize extreme environments (Bang et al. 2018). Holobionts thus contribute to marine microbial diversity and possibly resilience in the context of global environmental changes (Troussellier et al. 2017) and it is paramount to include the holobiont concept in predictive models that investigate the consequences of human impacts on the marine realm and its biogeochemical cycles.

\section{Challenges and opportunities in marine holobiont research}

\section{Marine holobiont assembly and regulation}

Two critical challenges partially addressed by using model systems are 1) to decipher the factors determining holobiont composition and 2) to elucidate the impacts and roles of the different partners in these complex systems over time. Some marine organisms such as bivalves transmit part of the microbiota maternally (Bright and 
Bulgheresi 2010; Funkhouser and Bordenstein 2013). In other marine holobionts, vertical transmission may be weak and inconsistent, whereas mixed modes of transmission (vertical and horizontal) or intermediate modes (pseudo-vertical, where horizontal acquisition frequently involves symbionts of parental origin) are more common (Björk et al. 2019). Identifying the factors shaping holobiont composition and understanding their evolution is highly relevant for marine organisms given that most marine hosts display a high specificity for their microbiota and even patterns of phylosymbiosis (Kazamia et al. 2016; Brooks et al. 2016; Pollock et al. 2018), despite a highly connected and microbe-rich environment.

During microbiota transmission (whether vertical or horizontal), selection by the host and/or by other components of the microbiome, is a key process in establishing or maintaining a holobiont microbial community that is distinct from the environment. The immune system of the host is one way of performing this selection in both marine and terrestrial holobionts. Perturbations in the transmission or the recruitment of the microbiota can lead to dysbiosis, and eventually microbial infections (Selosse et al. 2014; de Lorgeril et al. 2018). Dysbiotic individuals frequently display higher variability in their microbial community composition than healthy individuals, an observation in line with the "Anna Karenina principle" (Zaneveld et al. 2017), although there are exceptions to this rule (e.g. Marzinelli et al. 2015). A specific case of dysbiosis is the so-called "Rasputin effect" where benign endosymbionts opportunistically become detrimental to the host due to processes such as reduction in immune response under food deprivation, coinfections, or environmental pressure (Overstreet and Lotz 2016). Many diseases are now interpreted as the result of a microbial imbalance and the rise of opportunistic or polymicrobial infections upon host stress (Egan and Gardiner 2016). For instance in reefbuilding corals, warming destabilizes cnidarian-dinoflagellate associations, and some beneficial Symbiodiniacea strains switch their physiology and sequester more resources for their own growth at the expense of the coral host, leading to coral bleaching and even death (Baker et al. 2018).

Another way of selecting a holobiont microbial community is by chemically mediated microbial gardening. This concept has been demonstrated for land plants, where root exudates manipulate microbiome composition (Lebeis et al. 2015). In marine environments, the phylogenetic diversity of hosts and symbionts suggests both conserved and marine-specific chemical interactions, but studies are still in their infancy. For instance, seaweeds can chemically garden beneficial microbes, facilitating normal morphogenesis and increasing disease resistance (Kessler et al. 2018; Saha and Weinberger 2019), and seaweeds and corals structure their surface-associated microbiome by producing chemo-attractants and anti-bacterial compounds (Harder et al. 
2012; Ochsenkühn et al. 2018). There are fewer examples of chemical gardening in unicellular hosts, but it seems highly likely that similar processes are in place (Gribben et al. 2017; Cirri and Pohnert 2019).

In addition to selection, ecological drift, dispersal and evolutionary diversification have been proposed as key processes in community assembly, but are difficult to estimate in microbial communities (Nemergut et al. 2013). The only data currently at our disposal to quantify these processes are the diversity and distribution of microbes. Considering the high connectivity of aquatic environments, differences in marine microbial communities are frequently attributed to a combination of selection and drift, rather than limited dispersal (e.g. Burke, Steinberg, et al. 2011), a conclusion which, in the future, could be refined by conceptual models developed for instance for soil microbial communities (Stegen et al. 2013; Dini-Andreote et al. 2015). Diversification is mainly considered in the sense of coevolution or adaptation to host selection, which may also be driven by the horizontal acquisition of genes. However, co-speciation is challenging to prove (de Vienne et al. 2013; Moran and Sloan 2015) and only few studies have examined this process in marine holobionts to date, each focused on a restricted number of actors (e.g. Peek et al. 1998; Lanterbecq et al. 2010).

Increasing our knowledge on the contribution of these processes to holobiont community assembly in marine systems is a key challenge, which is of particular urgency today in the context of ongoing global change. Moreover, understanding how the community and functional structure of resident microbes are resilient to perturbations remains critical to predict and promote the health of their host and the ecosystem. Yet, the contribution of the microbiome is still missing in most quantitative models predicting the distribution of marine macro-organisms, or additional information on biological interactions would be required to make the former more accurate (Bell et al. 2018).

\section{Integrating marine model systems with large-scale studies}

By compiling a survey of the most important trends and challenges in the field of marine holobiont research (Figure 3), we identified two distinct opinion clusters: one focused on mechanistic understanding and work with model systems whereas another targets large-scale and heterogeneous data set analyses and predictive modeling. This illustrates that, on the one hand, the scientific community is interested in the establishment of models for the identification of specific molecular interactions between marine organisms at a given point in space and time, up to the point of synthesizing functional mutualistic communities in vitro (Kubo et al. 2013). On the other hand, another 

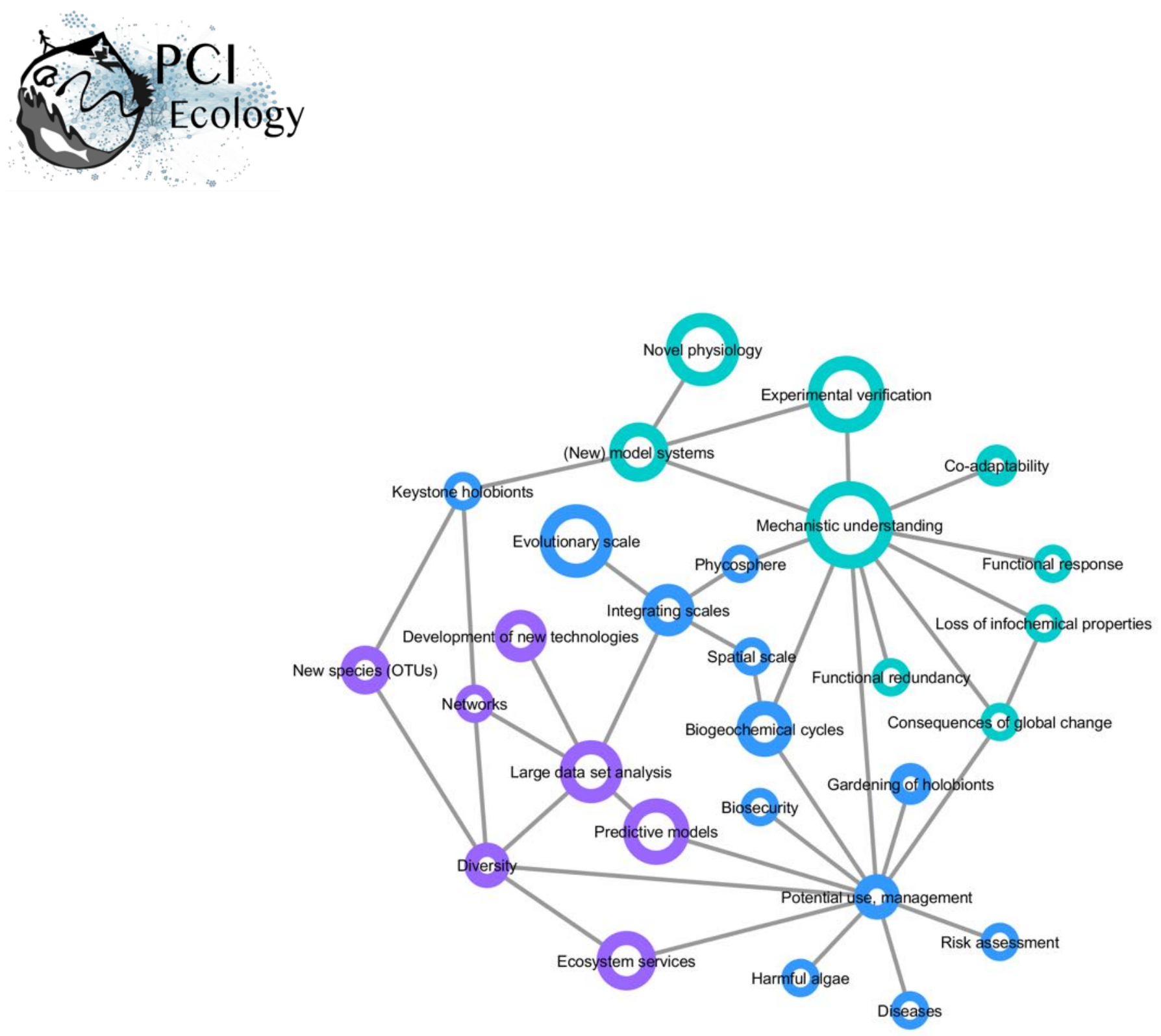

Figure 3: Mind map of key concepts, techniques, and challenges related to marine holobionts. The basis of this map was generated during the Holomarine workshop held in Roscoff in 2018 (https://www.euromarinenetwork.eu/activities/HoloMarine). The size of the nodes reflects the number of votes each keyword received from the participants of the workshop (total of 120 votes from 30 participants). The two main clusters corresponding to predictive modeling and mechanistic modeling, are displayed in purple and turquoise, respectively. Among the intermediate nodes linking these disciplines (blue) "potential use, management" was the most connected.

part of the community is moving towards global environmental sampling schemes such as the TARA Oceans expedition (Pesant et al. 2015) or the Ocean Sampling Day (Kopf et al. 2015), and towards long-term data series (e.g. Wiltshire et al. 2010; Harris 2010). What emerges as both lines of research progress is the understanding that small-scale functional studies in the laboratory are inconsequential unless made applicable to ecologicallyrelevant systems. At the same time, and despite the recent advances in community 
modeling (Ovaskainen et al. 2017), hypotheses drawn from large scale-studies remain correlative and require experimental validation of the mechanisms driving the observed processes. We illustrate the importance of integrating both approaches in Figure 3, where the node related to potential applications was perceived as a central hub at the interface between mechanistic understanding and predictive modeling.

A successful example merging both functional and large-scale approaches, are the root nodules of legumes, which harbor nitrogen-fixing bacteria. In this system, the functioning, distribution, and to some extent the evolution of these nodules, are now well understood (Epihov et al. 2017). The integration of this knowledge into agricultural practices has led to substantial yield improvements (e.g. Kavimandan 1985; Alam et al. 2015). In the more diffuse and partner-rich system of mycorrhizal symbioses between plant roots and soil fungi, a better understanding of the interactions has also been achieved via the investigation of environmental diversity patterns in combination with experimental culture systems with reduced diversity (van der Heijden et al. 2015).

We advocate the implementation of comparable efforts in marine sciences through interdisciplinary research combining physiology, biochemistry, ecology, and computational modeling. A key factor will be the identification and development of tractable model systems for keystone holobionts that allow hypotheses generated by large-scale data sets to be tested in controlled experiments. Such approaches will enable the identification of organismal interaction patterns within holobionts and nested ecosystems. In addition to answering fundamental questions, they will help address the ecological, societal, and ethical issues that arise from attempting to actively manipulate holobionts (e.g. in aquaculture, conservation, and invasion) in order to enhance their resilience and protect them from the impacts of global change (Llewellyn et al. 2014).

\section{Emerging methodologies to approach the complexity of holobiont partnerships}

As our conceptual understanding of the different levels of holobiont organization evolves, so does the need for multidisciplinary approaches and the development of tools and technologies to handle the unprecedented amount of data and their integration into dedicated ecological and evolutionary models. Here, progress is often fast-paced and provides exciting opportunities to address some of the challenges in holobiont research.

A giant technological stride has been the explosion of affordable '-omics' technologies allowing molecular ecologists to move from metabarcoding (i.e. sequencing of a taxonomic marker) to metagenomics or single-cell genomics, metatranscriptomics, 


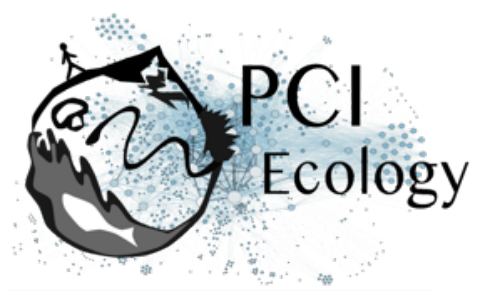

and metaproteomics, thus advancing our research from phylogenetic to functional analyses of the holobiont (Bowers et al. 2017; Meng et al. 2018; Figure 4). These approaches are equally useful in marine and in terrestrial environments, but the scarcity of well-studied lineages in the former makes the generation of good annotations and reference databases challenging for marine biologists. Metaproteomics combined with stable isotope fingerprinting can help study the metabolism of single lineages within the holobiont (Kleiner et al. 2018). In parallel, meta-metabolomics approaches have advanced over the last decades, and can be used to unravel the chemical interactions between partners. One limitation particularly relevant to marine systems is that many compounds are often not referenced in the mostly terrestrial-based databases, although recent technological advances such as molecular networking and meta-mass shift chemical profiling to identify relatives of known molecules may help to overcome this challenge (Hartmann et al. 2017).

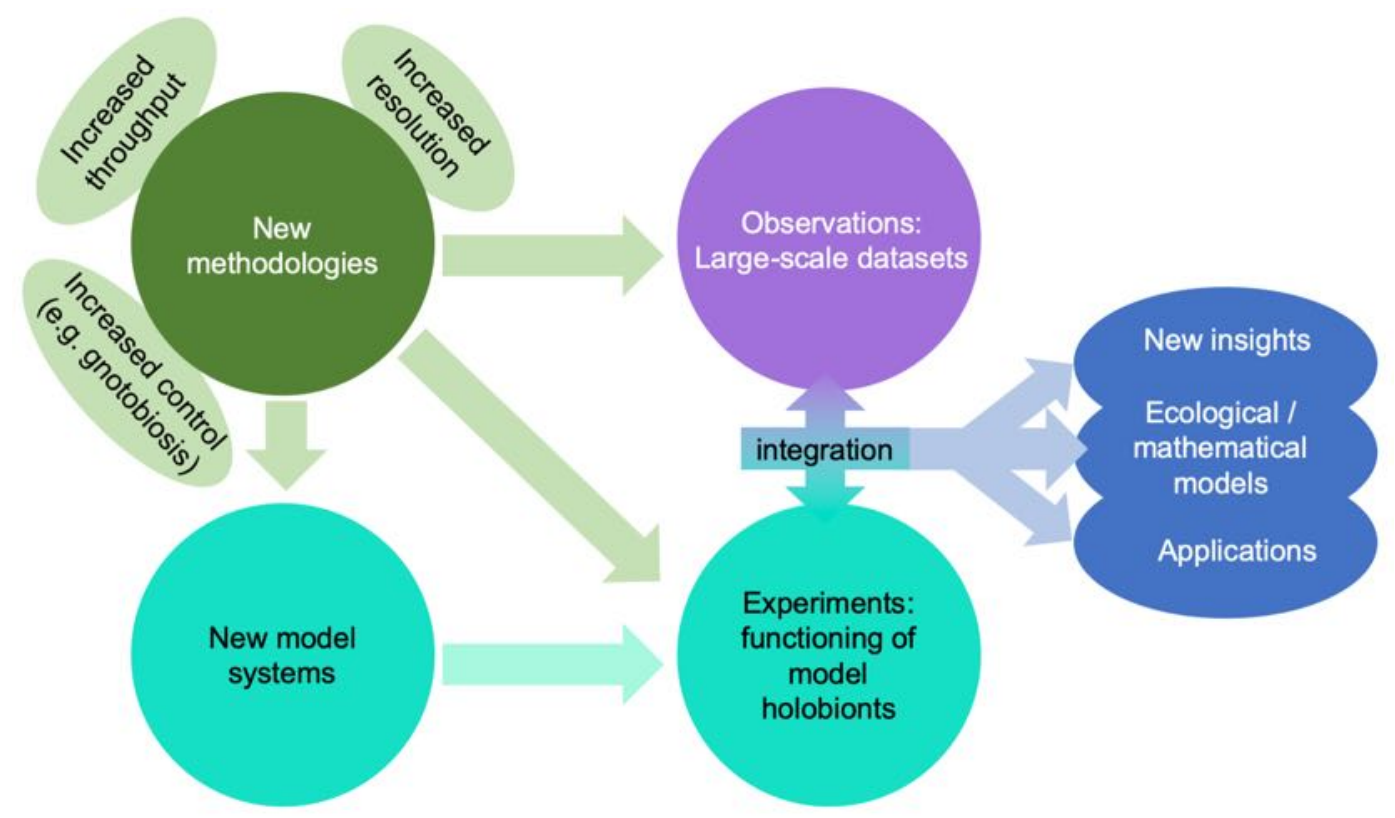

Figure 4: Impact of emerging methodologies (light green) on the main challenges in marine holobiont research identified in this paper (blue). Turquoise and purple correspond to the two main clusters of activity identified in Figure 3.

A further challenge in holobiont research is to identify the origin of compounds among the different partners of the holobionts and to determine their involvement in the maintenance and performance of the holobiont system. Well-designed experimental setups may help answer some of these questions (e.g. Quinn et al. 2016), but they will also 
require high levels of replication in order to represent the extensive intra-species variability found in marine systems. Recently developed in vivo and in situ imaging techniques combined with 'omics' approaches can provide small-scale spatial and qualitative information (origin, distribution, and concentration of a molecule or nutrient), shedding new light on the contribution of each partner of the holobiont system at the molecular level (e.g. Geier et al. 2020). The combination of stable isotope labelling and chemical imaging (mass spectrometry imaging such as secondary ion mass spectrometry and matrix-assisted laser desorption ionization, and synchrotron X-ray fluorescence) is particularly valuable in this context, as it enables the investigation of metabolic exchange between the different compartments of a holobiont (Musat et al. 2016; Raina et al. 2017). Finally, three-dimensional electron microscopy may help evaluate to what extent different components of a holobiont are physically integrated (Colin et al. 2017; Decelle et al. 2019), where high integration is one indication of highly specific interactions. All of these techniques can be employed in both marine and terrestrial systems, but in marine systems the high phylogenetic diversity of organisms adds to the complexity of adapting and optimizing these techniques.

One consequence of the development of such new methods is the feedback they provide to improve existing models or to develop entirely new ones, e.g. by conceptualizing holobionts as the combination of the interactions between the host and its microbiota (Skillings 2016; Berry and Loy 2018), or by redefining boundaries between the holobiont and its environment (Zengler and Palsson 2012). Such models may incorporate metabolic complementarity between different components of the holobiont (Dittami et al. 2014; Bordron et al. 2016), or simulate microbial communities starting from different cohorts of randomly generated microbes for comparison with actual metatranscriptomics and/or metagenomics data (Coles et al. 2017).

A side-effect of these recent developments has been to move holobiont research away from laboratory culture-based experiments. We argue that maintaining or even extending cultivation efforts, possibly via the implementation of "culturomics" approaches as successfully carried out for the human gut microbiome (Lagier et al. 2012), remains essential to capture the maximum holobiont biodiversity possible and will facilitate the experimental testing of hypotheses and the investigation of physiological mechanisms. A striking example of the importance of laboratory experimentation is the way germ-free mice re-inoculated with cultivated bacteria (the so-called gnotobiotic mice) have contributed to the understanding of interactions within the holobiont in animal health, physiology, and behavior (e.g. Neufeld et al. 2011; Faith et al. 2014; Selosse et al. 2014). Innovations in cultivation techniques for axenic (or germ-free) hosts (e.g. Spoerner et al. 2012) or in microbial cultivation such as microfluidic systems (e.g. Pan et al. 2011) and 


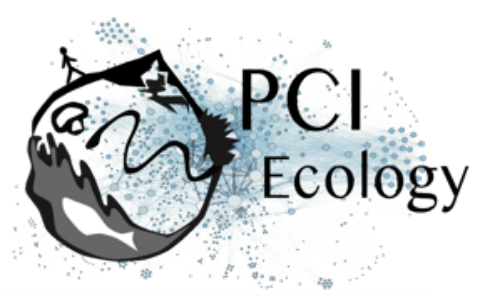

cultivation chips (Nichols et al. 2010) may provide a way to obtain pure cultures. Yet, bringing individual components of holobionts into cultivation can still be a daunting challenge due to the strong interdependencies between organisms as well as the existence of yet unknown metabolic processes that may have specific requirements. In this context, single-cell '-omics' analyses can provide critical information on some of the growth requirements of the organisms, and complement approaches of high-throughput culturing (Gutleben et al. 2018). Established cultures can then be developed into model systems, e.g. by genome sequencing and the development of genetic tools, in order to move towards mechanistic understanding and experimental testing of hypothetical processes within the holobiont derived from environmental meta'-omics' approaches. A few such model systems have already been mentioned above, but '-omics' techniques have the potential to broaden the range of available models, enabling a better understanding of the functioning of marine holobionts and their interactions in marine environments (Wichard and Beemelmanns 2018).

\section{Ecosystem services and holobionts in natural and managed systems}

A better understanding of marine holobionts will likely have direct socio-economic consequences for coastal marine ecosystems, estimated to provide services worth almost 50 trillion $\left(10^{12}\right.$ ) US\$ per year (Costanza et al. 2014). Most of the management practices in marine systems have so far been based exclusively on the biology and ecology of macroorganisms. A multidisciplinary approach that provides mechanistic understanding of habitat-forming organisms as holobionts will ultimately improve the predictability and management of coastal ecosystems. For example, host-associated microbiota could be integrated in biomonitoring programs as proxies used to assess the health of ecosystems. Microbial shifts and dysbiosis constitute early warning signals that may allow managers to predict potential impacts and intervene more rapidly and effectively (van Oppen et al. 2017; Marzinelli et al. 2018).

One form of intervention could be to promote positive changes of host-associated microbiota, in ways analogous to the use of pre- and/or probiotics in humans (Singh et al. 2013) or inoculation of beneficial microbes in plant farming (Berruti et al. 2015; van der Heijden et al. 2015). In macroalgae, beneficial bacteria identified from healthy seaweed holobionts could be used as biological control agents and applied to diseased plantlets in order to suppress the growth of bacteria detrimental to the host and to prevent disease outbreaks in aquaculture settings. In addition to bacteria, these macroalgae frequently host endophytic fungi that may have protective functions for the algae (Porras-Alfaro and 
Bayman 2011; Vallet et al. 2018). Host-associated microbiota could also be manipulated to shape key phenotypes in cultured marine organisms. For example, specific bacteria associated with microalgae may enhance algal growth (Amin et al. 2009; Kazamia et al. 2012; Le Chevanton et al. 2013), increase lipid content (Cho et al. 2015), and participate in the bioprocessing of algal biomass (Lenneman et al. 2014). More recently, the active modification of the coral microbiota has even been advocated as a means to boost the resilience of the holobiont to climate change (van Oppen et al. 2015; Peixoto et al. 2017), an approach which would, however, bear a high risk of unanticipated and unintended side effects.

Also, holistic approaches could be implemented in the framework of fish farms. Recent developments including integrated multi-trophic aquaculture, recirculating aquaculture, offshore aquaculture, species selection, and breeding increase yields and reduce the resource constraints and environmental impacts of intensive aquaculture (Klinger and Naylor 2012). However, the intensification of aquaculture often goes hand in hand with increased amounts of disease outbreaks both in industry and wild stocks. A holistic microbial management approach, e.g. by reducing the use of sterilization procedures and favoring the selection of healthy and stable microbiota consisting of slowgrowing K-strategists, may provide an efficient solution to these latter problems, reducing the sensitivity of host to opportunistic pathogens (De Schryver and Vadstein 2014).

Nevertheless, when considering their biotechnological potential, it should also be noted that marine microbiota are likely vulnerable to anthropogenic influences and that their deliberate engineering, introduction from exotic regions (often hidden in their hosts), or inadvertent perturbations may have profound, and yet entirely unknown, consequences for marine ecosystems. Terrestrial environments provide numerous examples of unwanted plant expansions or ecosystem perturbations linked to microbiota (e.g. Dickie et al. 2017), and cases where holobionts manipulated by human resulted in pests (e.g. Clay and Holah 1999) call for a cautious and ecologically-informed evaluation of holobiont-based technologies in marine systems.

\section{Conclusions}

Marine ecosystems represent highly connected reservoirs of largely unexplored biodiversity. They are of critical importance to feed the ever-growing world population, constitute significant players in global biogeochemical cycles but are also threatened by human activities and global change. In order to unravel some of the basic principles of life and its evolution, and to protect and sustainably exploit marine natural resources, it is 


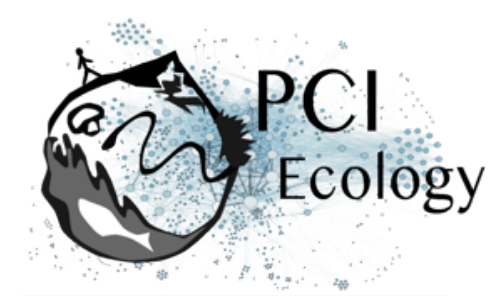

paramount to consider the complex biotic interactions that shape the marine communities and their environment. The scope of these interactions ranges from simple molecular signals between two partners, via complex assemblies of eukaryotes, prokaryotes, and viruses with one or several hosts, to entire ecosystems. Accordingly, current key questions in marine holobiont research cover a wide range of topics: What are the exchanges that occur between different partners of the holobiont, and how do they condition their survival, dynamics and evolution? What are the cues and signals driving these exchanges? What are the relevant units of selection and dispersal in marine holobionts? How do holobiont systems and the interactions within them change over time and in different conditions? How do such changes impact ecological processes? How can this knowledge be applied to our benefit and where do we need to draw limits? Identifying and consolidating key model systems while adapting emerging "-omics", imaging, and culturing technologies to them will be critical to the development of "holobiont-aware" ecosystem models.

We believe that the concept of holobionts will be most useful and heuristic if used with a degree of malleability. It not only represents the fundamental understanding that all living organisms have intimate connections with their immediate neighbors, which may impact all aspects of their biology, but also enables us to define units of interacting organisms that are most suitable to answer specific scientific, societal, and economic questions. The consideration of the holobiont concept marks a paradigm shift in biological and environmental sciences, but only if scientists work together as an (inter)active and transdisciplinary community bringing together holistic and mechanistic views. This will result in tangible outcomes including a better understanding of evolutionary and adaptive processes, improved modeling of habitats and understanding of biogeochemical cycles, as well as application of the holobiont concept in aquaculture and ecosystem management projects.

\section{Acknowledgements}

This paper is based on the results of a foresight workshop funded by the EuroMarine network, Sorbonne University, and the UMRs 8227 and 7144 of the Roscoff Biological Station. We are grateful to Catherine Boyen for useful advice and helpful discussions. We thank Sylvie Kwayeb-Fagon for workshop facilitation; Maryvonne Saout and Léna Corre for administrative support; and Marc Trousselier, Sébastien Villéger, Arthur Escalas, Yvan Bettarel, Thierry Bouvier for help writing a part of the manuscript. EMM was partially funded by an Australian Research Council Discovery Project (DP180104041), and 


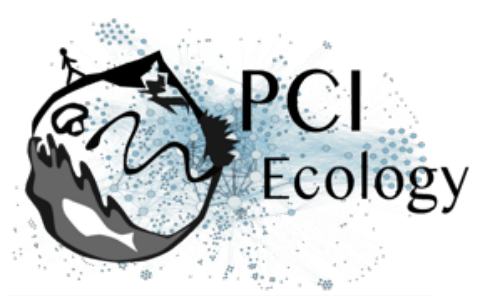

JP was partially funded by the Galician Innovation Agency (IN607A 2017/4). The work of SD ad CL was partially funded by the ANR project IDEALG (ANR-10-BTBR-04). CG, CL, and SD received funding from the European Union's Horizon 2020 research and innovation program under the Marie Sklodowska-Curie grant agreement number 624575 (ALFF). The work of FN was partially funded by the ANR project IMPEKAB (ANR-15-CE02-001). UC was partially funded by the Research Council of Lithuania project INBALANCE (09.3.3-LMT-K712-01-0069). JD was supported by the LabEx GRAL (ANR-10-LABX-49-01) and Pôle CBS from the University of Grenoble Alpes. PC received support from the European Union's Horizon 2020 research and innovation program through the SponGES project (grant agreement No. 679849). EKAZ was funded by a Marie Curie Individual Fellowship (Horizon 2020, IRONCOMM). AHE was supported by Portuguese national funds from FCT Foundation for Science and Technology through projects UID/Multi/04326/2019 and UIDB/04326/2020. This document reflects only the authors' view and the Executive Agency for Small and Medium-sized Enterprises (EASME) is not responsible for any use that may be made of the information it contains. This preprint has been peer-reviewed and recommended by Peer Community In Ecology

(https://doi.org/10.24072/pci.ecology.100045)

\section{Conflict of interest disclosure}

The authors of this preprint declare that they have no financial conflict of interest with the content of this article. $\mathrm{FN}$ is one of the $\mathrm{PCI}$ Ecology recommenders.

\section{References}

Alam F, Kim TY, Kim SY, et al. 2015. Effect of molybdenum on nodulation, plant yield and nitrogen uptake in hairy vetch (Vicia villosa Roth). Soil Science and Plant Nutrition 61: 664-675.

Amin SA, Green DH, Hart MC, Küpper FC, Sunda WG, Carrano CJ. 2009. Photolysis of ironsiderophore chelates promotes bacterial-algal mutualism. Proceedings of the National Academy of Sciences of the United States of America 106: 17071-6.

Amin SA, Parker MS, Armbrust EV. 2012. Interactions between diatoms and bacteria. Microbiology and Molecular Biology Reviews 76: 667-84.

Anantharaman K, Brown CT, Hug LA, et al. 2016. Thousands of microbial genomes shed light on interconnected biogeochemical processes in an aquifer system. Nature Communications 7: 13219.

Arboleda E, Hartenstein V, Martinez P, et al. 2018. An emerging system to study photosymbiosis, brain regeneration, chronobiology, and behavior: the marine acoel Symsagittifera roscoffensis. BioEssays 40: 1800107. 


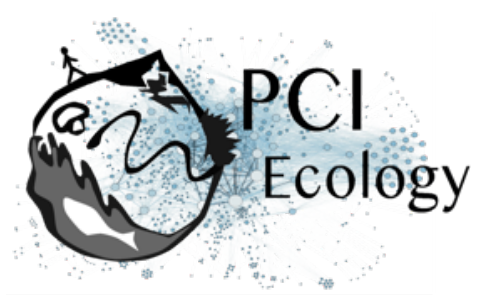

Archibald JM. 2015. Endosymbiosis and eukaryotic cell evolution. Current Biology 25: R911-R921.

Baker DM, Freeman CJ, Wong JCY, Fogel ML, Knowlton N. 2018. Climate change promotes parasitism in a coral symbiosis. ISME Journal 12: 921-930.

Bang C, Dagan T, Deines P, et al. 2018. Metaorganisms in extreme environments: do microbes play a role in organismal adaptation? Zoology 127: 1-19.

Baumgarten S, Simakov O, Esherick LY, et al. 2015. The genome of Aiptasia, a sea anemone model for coral symbiosis. Proceedings of the National Academy of Sciences of the United States of America 112: 11893-8.

Bell JJ, Rovellini A, Davy SK, et al. 2018. Climate change alterations to ecosystem dominance: how might sponge-dominated reefs function? Ecology 99: 1920-1931.

Bennett AF, Haslem A, Cheal DC, et al. 2009. Ecological processes: a key element in strategies for nature conservation. Ecological Management \& Restoration 10: 192-199.

Berkelmans R, van Oppen MJH. 2006. The role of zooxanthellae in the thermal tolerance of corals: a "nugget of hope" for coral reefs in an era of climate change. Proceedings of the Royal Society B: Biological Sciences 273: 2305-12.

Berruti A, Lumini E, Balestrini R, Bianciotto V. 2015. Arbuscular mycorrhizal fungi as natural biofertilizers: let's benefit from past successes. Frontiers in Microbiology 6: 1559.

Berry D, Loy A. 2018. Stable-isotope probing of human and animal microbiome function. Trends in Microbiology 26: 999-1007.

Björk JR, Díez-Vives C, Astudillo-García C, Archie EA, Montoya JM. 2019. Vertical transmission of sponge microbiota is inconsistent and unfaithful. Nature Ecology \& Evolution 3: 1172-1183.

Bonaglia S, Brüchert V, Callac N, Vicenzi A, Chi Fru E, Nascimento FJA. 2017. Methane fluxes from coastal sediments are enhanced by macrofauna. Scientific Reports 7: 13145.

Bordron $\mathbf{P}$, Latorre $\mathbf{M}$, Cortés $\mathbf{M}-\mathbf{P}$, et al. 2016. Putative bacterial interactions from metagenomic knowledge with an integrative systems ecology approach. MicrobiologyOpen 5: 106-117.

Bouchard Marmen M, Kenchington E, Ardyna M, Archambault P. 2017. Influence of seabird colonies and other environmental variables on benthic community structure, Lancaster Sound region, Canadian Arctic. Journal of Marine Systems 167: 105-117.

Bowers RM, Doud DFR, Woyke T. 2017. Analysis of single-cell genome sequences of bacteria and archaea. Emerging Topics in Life Sciences 1: 249-255.

Bright M, Bulgheresi S. 2010. A complex journey: transmission of microbial symbionts. Nature Reviews. Microbiology 8: 218-30.

Brooks AW, Kohl KD, Brucker RM, van Opstal EJ, Bordenstein SR. 2016. Phylosymbiosis: relationships and functional effects of microbial communities across host evolutionary history. PLOS Biology 14: e2000225.

Bulgarelli D, Schlaeppi K, Spaepen S, Ver Loren van Themaat E, Schulze-Lefert P. 2013. Structure and functions of the bacterial microbiota of plants. Annual Review of Plant Biology 64: 80738.

Burke C, Steinberg P, Rusch D, Kjelleberg S, Thomas T. 2011. Bacterial community assembly based on functional genes rather than species. Proceedings of the National Academy of Sciences of the United States of America 108: 14288-93.

Burke C, Thomas T, Lewis M, Steinberg P, Kjelleberg S. 2011. Composition, uniqueness and variability of the epiphytic bacterial community of the green alga Ulva australis. ISME journal 5: 590-600.

Cardini U, Bednarz VN, Naumann MS, et al. 2015. Functional significance of dinitrogen fixation in sustaining coral productivity under oligotrophic conditions. Proceedings of the Royal Society 
B: Biological Sciences 282: 20152257.

Le Chevanton M, Garnier M, Bougaran G, et al. 2013. Screening and selection of growth-promoting bacteria for Dunaliella cultures. Algal Research 2: 212-222.

Chiarello M, Auguet J-C, Bettarel Y, et al. 2018. Skin microbiome of coral reef fish is highly variable and driven by host phylogeny and diet. Microbiome 6: 147.

Cho D-H, Ramanan R, Heo J, et al. 2015. Enhancing microalgal biomass productivity by engineering a microalgal-bacterial community. Bioresource Technology 175: 578-585.

Cirri E, Pohnert G. 2019. Algae-bacteria interactions that balance the planktonic microbiome. New Phytologist 223: 100-106.

Clay K, Holah J. 1999. Fungal endophyte symbiosis and plant diversity in successional fields. Science 285: 1742-1744.

Coles VJ, Stukel MR, Brooks MT, et al. 2017. Ocean biogeochemistry modeled with emergent traitbased genomics. Science 358: 1149-1154.

Colin S, Coelho LP, Sunagawa S, et al. 2017. Quantitative 3D-imaging for cell biology and ecology of environmental microbial eukaryotes. elife 6: e26066.

Cooper MB, Kazamia E, Helliwell KE, et al. 2019. Cross-exchange of B-vitamins underpins a mutualistic interaction between Ostreococcus tauri and Dinoroseobacter shibae. ISME Journal 13: 334-345.

Costanza R, de Groot R, Sutton P, et al. 2014. Changes in the global value of ecosystem services. Global Environmental Change 26: 152-158.

Decelle J, Colin S, Foster RA. 2015. Marine protists In: Ohtsuka S, Suzaki T, Horiguchi T, Suzuki N, Not $\mathrm{F}$, eds. Marine Protists. Tokyo: Springer Japan, 465-500.

Decelle J, Stryhanyuk H, Gallet B, et al. 2019. Algal remodeling in a ubiquitous planktonic photosymbiosis. Current Biology 29: 968.

Dicke M, Sabelis MW. 1988. Infochemical terminology: based on cost-benefit analysis rather than origin of compounds? Functional Ecology 2: 131.

Dickie IA, Bufford JL, Cobb RC, et al. 2017. The emerging science of linked plant-fungal invasions. New Phytologist 215: 1314-1332.

Dini-Andreote F, Stegen JC, van Elsas JD, Salles JF. 2015. Disentangling mechanisms that mediate the balance between stochastic and deterministic processes in microbial succession. Proceedings of the National Academy of Sciences of the USA 112: E1326-32.

Dittami SM, Duboscq-Bidot LL, Perennou M, et al. 2016. Host-microbe interactions as a driver of acclimation to salinity gradients in brown algal cultures. ISME Journal 10: 51-63.

Dittami SM, Eveillard D, Tonon T. 2014. A metabolic approach to study algal-bacterial interactions in changing environments. Molecular Ecology 23: 1656-1660.

Douglas AE, Werren JH. 2016. Holes in the hologenome: why host-microbe symbioses are not holobionts. mBio 7: e02099.

Dubilier N, Bergin C, Lott C. 2008. Symbiotic diversity in marine animals: the art of harnessing chemosynthesis. Nature Reviews Microbiology 6: 725-740.

Duperron S, Halary S, Lorion J, Sibuet M, Gaill F. 2008. Unexpected co-occurrence of six bacterial symbionts in the gills of the cold seep mussel Idas sp. (Bivalvia: Mytilidae). Environmental Microbiology 10: 433-445.

Egan S, Gardiner M. 2016. Microbial dysbiosis: rethinking disease in marine ecosystems. Frontiers in Microbiology 7: 991.

Epihov DZ, Batterman SA, Hedin LO, Leake JR, Smith LM, Beerling DJ. 2017. N2-fixing tropical legume evolution: a contributor to enhanced weathering through the Cenozoic? Proceedings 
of the Royal Society B: Biological Sciences 284: 20170370.

Faith JJ, Ahern PP, Ridaura VK, Cheng J, Gordon JI. 2014. Identifying gut microbe-host phenotype relationships using combinatorial communities in gnotobiotic mice. Science Translational Medicine 6: 220ra11.

Falkowski PG, Fenchel T, Delong EF. 2008. The microbial engines that drive Earth's biogeochemical cycles. Science 320: 1034-1039.

Faure D, Simon J-C, Heulin T. 2018. Holobiont: a conceptual framework to explore the ecoevolutionary and functional implications of host-microbiota interactions in all ecosystems. New Phytologist 218: 1321-1324.

Fiore CL, Jarett JK, Olson ND, Lesser MP. 2010. Nitrogen fixation and nitrogen transformations in marine symbioses. Trends in Microbiology 18: 455-463.

Funkhouser L, Bordenstein SR. 2013. Mom knows best: the universality of maternal microbial transmission. PLoS Biology 11: e1001631.

Geier B, Sogin EM, Michellod D, et al. 2020. Spatial metabolomics of in situ host-microbe interactions at the micrometre scale. Nature Microbiology: 1-13.

Gilbert SF, McDonald E, Boyle $\mathbf{N}$, et al. 2010. Symbiosis as a source of selectable epigenetic variation: taking the heat for the big guy. Philosophical Transactions of the Royal Society $B$ : Biological Sciences 365: 671-678.

Godoy O, Bartomeus I, Rohr RP, Saavedra S. 2018. Towards the integration of niche and network theories. Trends in Ecology \& Evolution 33: 287-300.

de Goeij JM, van Oevelen D, Vermeij MJA, et al. 2013. Surviving in a marine desert: the sponge loop retains resources within coral reefs. Science 342: 108-10.

Gregory AC, Zayed AA, Conceição-Neto N, et al. 2019. Marine DNA viral macro- and microdiversity from pole to pole. Cell 177: 1109-1123.e14.

Gribben PE, Nielsen S, Seymour JR, Bradley DJ, West MN, Thomas T. 2017. Microbial communities in marine sediments modify success of an invasive macrophyte. Scientific Reports 7: 9845.

Guimarães PR, Pires MM, Jordano P, Bascompte J, Thompson JN. 2017. Indirect effects drive coevolution in mutualistic networks. Nature 550: 511-514.

Gutleben J, Chaib De Mares M, van Elsas JD, Smidt H, Overmann J, Sipkema D. 2018. The multiomics promise in context: from sequence to microbial isolate. Critical Reviews in Microbiology 44: 212-229.

Hale MG, Lindsey DL, Hameed KM. 1973. Gnotobiotic culture of plants and related research. The Botanical Review 39: 261-273.

Harder T, Campbell AH, Egan S, Steinberg PD. 2012. Chemical mediation of ternary interactions between marine holobionts and their environment as exemplified by the red alga Delisea pulchra. Journal of Chemical Ecology 38: 442-450.

Harris R. 2010. The L4 time-series: the first 20 years. Journal of Plankton Research 32: 577-583.

Hartmann AC, Petras D, Quinn RA, et al. 2017. Meta-mass shift chemical profiling of metabolomes from coral reefs. Proceedings of the National Academy of Sciences of the United States of America 114: 11685-11690.

van der Heijden MGA, Martin FM, Selosse M-A, Sanders IR. 2015. Mycorrhizal ecology and evolution: the past, the present, and the future. New Phytologist 205: 1406-1423.

Hoitink H, Boehm M. 1999. Biocontrol within the context of soil microbial communities: a substrate-dependent phenomenon. Annual Review of Phytopathology 37: 427-446.

Hollants J, Leliaert F, Verbruggen H, De Clerck O, Willems A. 2013. Host specificity and coevolution of Flavobacteriaceae endosymbionts within the siphonous green seaweed Bryopsis. Molecular 
Phylogenetics and Evolution 67: 608-614.

Holt EA, Miller SW. 2010. Bioindicators: using organisms to measure environmental impacts. Nature Education Knowledge 3: 8.

Kavimandan SK. 1985. Root nodule bacteria to improve yield of wheat (Triticum aestivum L.). Plant and Soil 86: 141-144.

Kazamia E, Aldridge DC, Smith AG. 2012. Synthetic ecology - A way forward for sustainable algal biofuel production? Journal of Biotechnology 162: 163-169.

Kazamia E, Helliwell KE, Purton S, Smith AG. 2016. How mutualisms arise in phytoplankton communities: building eco-evolutionary principles for aquatic microbes. Ecology Letters 19: 810-822.

Kelty MO, Cook CB. 1976. Survival during starvation of symbiotic, aposymbiotic, and non-symbiotic Hydra In: Coelenterate Ecology and Behavior. Boston, MA: Springer, 409-414.

Kessler RW, Weiss A, Kuegler S, Hermes C, Wichard T. 2018. Macroalgal-bacterial interactions: Role of dimethylsulfoniopropionate in microbial gardening by Ulva (Chlorophyta). Molecular Ecology 27: 1808-1819.

Kinlan BP, Gaines SD. 2003. Propagule dispersal in marine and terrestrial environments: a community perspective. Ecology 84: 2007-2020.

Kleiner M, Dong X, Hinzke T, et al. 2018. Metaproteomics method to determine carbon sources and assimilation pathways of species in microbial communities. Proceedings of the National Academy of Sciences of the United States of America 115: E5576-E5584.

Klinger D, Naylor R. 2012. Searching for solutions in aquaculture: charting a sustainable course. Annual Review of Environment and Resources 37: 247-276.

Kopf A, Bicak M, Kottmann R, et al. 2015. The ocean sampling day consortium. GigaScience 4: 27.

Kubo I, Hosoda K, Suzuki S, et al. 2013. Construction of bacteria-eukaryote synthetic mutualism. Biosystems 113: 66-71.

Lagier JC, Armougom F, Million M, et al. 2012. Microbial culturomics: Paradigm shift in the human gut microbiome study. Clinical Microbiology and Infection 18: 1185-1193.

Lanterbecq D, Rouse GW, Eeckhaut I. 2010. Evidence for cospeciation events in the host-symbiont system involving crinoids (Echinodermata) and their obligate associates, the myzostomids (Myzostomida, Annelida). Molecular Phylogenetics and Evolution 54: 357-371.

Lebeis SL, Paredes SH, Lundberg DS, et al. 2015. Salicylic acid modulates colonization of the root microbiome by specific bacterial taxa. Science 349: 860-864.

Lehnert EM, Burriesci MS, Pringle JR. 2012. Developing the anemone Aiptasia as a tractable model for cnidarian-dinoflagellate symbiosis: the transcriptome of aposymbiotic A. pallida. BMC Genomics 13: 271.

Lenneman EM, Wang P, Barney BM. 2014. Potential application of algicidal bacteria for improved lipid recovery with specific algae. FEMS Microbiology Letters 354: 102-110.

Leys SP, Kahn AS, Fang JKH, Kutti T, Bannister RJ. 2018. Phagocytosis of microbial symbionts balances the carbon and nitrogen budget for the deep-water boreal sponge Geodia barretti. Limnology and Oceanography 63: 187-202.

Llewellyn MS, Boutin S, Hoseinifar SH, Derome N. 2014. Teleost microbiomes: the state of the art in their characterization, manipulation and importance in aquaculture and fisheries. Frontiers in Microbiology 5: 207.

Loh J, Pierson EA, Pierson LS, Stacey G, Chatterjee A. 2002. Quorum sensing in plant-associated bacteria. Current Opinion in Plant Biology 5: 285-90.

de Lorgeril J, Lucasson A, Petton B, et al. 2018. Immune-suppression by OsHV-1 viral infection 
causes fatal bacteraemia in Pacific oysters. Nature Communications 9: 4215.

Madsen EL. 2011. Microorganisms and their roles in fundamental biogeochemical cycles. Current Opinion in Biotechnology 22: 456-464.

Marchesi JR, Ravel J. 2015. The vocabulary of microbiome research: a proposal. Microbiome 3: 31.

Margulis L, Fester R. 1991. Symbiosis as a Source of Evolutionary Innovation: Speciation and Morphogenesis. MIT Press.

Martin-Platero AM, Cleary B, Kauffman K, et al. 2018. High resolution time series reveals cohesive but short-lived communities in coastal plankton. Nature Communications 9: 266.

Martin W, Baross J, Kelley D, Russell MJ. 2008. Hydrothermal vents and the origin of life. Nature reviews. Microbiology 6: 805-14.

Martínez-Pérez C, Mohr W, Löscher CR, et al. 2016. The small unicellular diazotrophic symbiont, UCYN-A, is a key player in the marine nitrogen cycle. Nature Microbiology 1: 16163.

Marzinelli EM, Campbell AH, Zozaya Valdes E, et al. 2015. Continental-scale variation in seaweed host-associated bacterial communities is a function of host condition, not geography. Environmental Microbiology 17: 4078-4088.

Marzinelli EM, Qiu Z, Dafforn KA, Johnston EL, Steinberg PD, Mayer-Pinto M. 2018. Coastal urbanisation affects microbial communities on a dominant marine holobiont. Biofilms and Microbiomes 4: 1.

McFall-Ngai MJ. 2014. The importance of microbes in animal development: lessons from the squidVibrio symbiosis. Annual Review of Microbiology 68: 177-194.

McFall-Ngai M, Hadfield MG, Bosch TCG, et al. 2013. Animals in a bacterial world, a new imperative for the life sciences. Proceedings of the National Academy of Sciences of the United States of America 110: 3229-3236.

Meng A, Marchet C, Corre E, et al. 2018. A de novo approach to disentangle partner identity and function in holobiont systems. Microbiome 6: 105.

Mereschkowski C. 1905. Über Natur und Ursprung der Chromatophoren im Pflanzenreiche. Biologisches Centralblatt 25: 593-604.

Middelboe M, Brussaard CPD. 2017. Marine viruses: key players in marine ecosystems. Viruses $\mathbf{9}$ 302.

Millennium Ecosystem Assessment Panel T. 2005. Ecosystems and human well-being : synthesis / Millennium Ecosystem Assessment. Washington, USA: Island press.

Mitra A, Flynn KJ, Burkholder JM, et al. 2013. The role of mixotrophic protists in the biological carbon pump. Biogeosciences Discussions 10: 13535-13562.

Moran NA, Sloan DB. 2015. The hologenome concept: helpful or hollow? PLOS Biology 13: e1002311.

Musat N, Musat F, Weber PK, Pett-Ridge J. 2016. Tracking microbial interactions with NanoSIMS. Current Opinion in Biotechnology 41: 114-121.

Myers JH, Rothman LE. 1995. Virulence and transmission of infectious diseases in humans and insects: evolutionary and demographic patterns. TREE 10: 194-198.

Nardon P, Charles H. 2001. Morphological Aspects of Symbiosis In: Symbiosis. Dordrecht: Kluwer Academic Publishers, 13-44.

Nemergut DR, Schmidt SK, Fukami T, et al. 2013. Patterns and processes of microbial community assembly. Microbiology and Molecular Biology Reviews 77: 342-56.

Neufeld KM, Kang N, Bienenstock J, Foster JA. 2011. Reduced anxiety-like behavior and central neurochemical change in germ-free mice. Neurogastroenterology and Motility 23: 255-64, e119. 


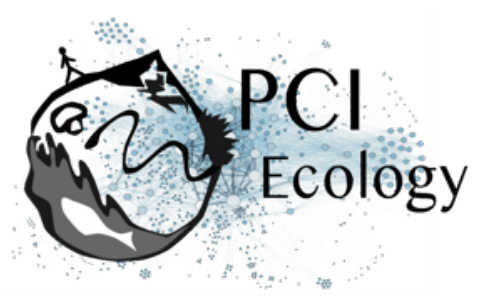

Nichols D, Cahoon N, Trakhtenberg EM, et al. 2010. Use of ichip for high-throughput in situ cultivation of "uncultivable" microbial species. Applied and Environmental Microbiology 76: 2445-50.

Not F, Probert I, Gerikas Ribeiro C, et al. 2016. Photosymbiosis in marine pelagic environments In: The Marine Microbiome. Cham: Springer International Publishing, 305-332.

O'Malley MA. 2017. From endosymbiosis to holobionts: Evaluating a conceptual legacy. Journal of Theoretical Biology 434: 34-41.

Ochsenkühn MA, Schmitt-Kopplin P, Harir M, Amin SA. 2018. Coral metabolite gradients affect microbial community structures and act as a disease cue. Communications Biology 1: 184.

Ohdera AH, Abrams MJ, Ames CL, et al. 2018. Upside-down but headed in the right direction: review of the highly versatile Cassiopea xamachana system. Frontiers in Ecology and Evolution 6: 35.

van Oppen MJH, Gates RD, Blackall LL, et al. 2017. Shifting paradigms in restoration of the world's coral reefs. Global Change Biology 23: 3437-3448.

van Oppen MJH, Oliver JK, Putnam HM, Gates RD. 2015. Building coral reef resilience through assisted evolution. Proceedings of the National Academy of Sciences of the United States of America 112: 2307-13.

Ovaskainen 0, Tikhonov G, Norberg A, et al. 2017. How to make more out of community data? A conceptual framework and its implementation as models and software. Ecology Letters 20: 561-576.

Overstreet RM, Lotz JM. 2016. Host-symbiont relationships: understanding the change from guest to pest In: Hurst CJ, ed. The Rasputin Effect: When Commensals and Symbionts Become Parasitic. Springer, Cham, 27-64.

Pan J, Stephenson AL, Kazamia E, et al. 2011. Quantitative tracking of the growth of individual algal cells in microdroplet compartments. Integrative Biology 3: 1043.

Peek AS, Feldman RA, Lutz RA, Vrijenhoek RC. 1998. Cospeciation of chemoautotrophic bacteria and deep sea clams. Proceedings of the National Academy of Sciences 95: 9962-9966.

Peixoto RS, Rosado PM, Leite DC de A, Rosado AS, Bourne DG. 2017. Beneficial microorganisms for corals (BMC): proposed mechanisms for coral health and resilience. Frontiers in Microbiology 8: 341.

Pesant S, Not F, Picheral M, et al. 2015. Open science resources for the discovery and analysis of Tara Oceans data. Scientific Data 2: 150023.

Petersen JM, Kemper A, Gruber-Vodicka H, et al. 2016. Chemosynthetic symbionts of marine invertebrate animals are capable of nitrogen fixation. Nature Microbiology 2: 16195.

Pita L, Rix L, Slaby BM, Franke A, Hentschel U. 2018. The sponge holobiont in a changing ocean: from microbes to ecosystems. Microbiome 6: 46.

Pollock FJ, McMinds R, Smith S, et al. 2018. Coral-associated bacteria demonstrate phylosymbiosis and cophylogeny. Nature Communications 9: 4921.

Ponnudurai R, Kleiner M, Sayavedra L, et al. 2017. Metabolic and physiological interdependencies in the Bathymodiolus azoricus symbiosis. ISME Journal 11: 463-477.

Porras-Alfaro A, Bayman P. 2011. Hidden fungi, emergent properties: endophytes and microbiomes. Annual Review of Phytopathology 49: 291-315.

Quinn RA, Vermeij MJA, Hartmann AC, et al. 2016. Metabolomics of reef benthic interactions reveals a bioactive lipid involved in coral defence. Proceedings of the Royal Society B: Biological Sciences 283: 20160469.

Raina J-B, Clode PL, Cheong S, et al. 2017. Subcellular tracking reveals the location of 
dimethylsulfoniopropionate in microalgae and visualises its uptake by marine bacteria. elife 6: e23008.

Raina J-B, Tapiolas D, Willis BL, Bourne DG. 2009. Coral-associated bacteria and their role in the biogeochemical cycling of sulfur. Applied and Environmental Microbiology 75: 3492-501.

Rix L, de Goeij JM, van Oevelen D, et al. 2017. Differential recycling of coral and algal dissolved organic matter via the sponge loop. Functional Ecology 31: 778-789.

Rohwer F, Seguritan V, Azam F, Knowlton N. 2002. Diversity and distribution of coral-associated bacteria. Marine Ecology Progress Series 243: 1-10.

Rolland J-L, Stien D, Sanchez-Ferandin S, Lami R. 2016. Quorum sensing and quorum quenching in the phycosphere of phytoplankton: a case of chemical interactions in ecology. Journal of Chemical Ecology 42: 1201-1211.

Rosenberg E, Koren O, Reshef L, Efrony R, Zilber-Rosenberg I. 2007a. The role of microorganisms in coral health, disease and evolution. Nature Reviews Microbiology 5: 355-362.

Rosenberg E, Koren O, Reshef L, Efrony R, Zilber-Rosenberg I. 2007b. The hologenome theory disregards the coral holobiont: reply from Rosenberg et al. Nature Reviews Microbiology 5: 826-826.

Rosenberg E, Sharon G, Atad I, Zilber-Rosenberg I. 2010. The evolution of animals and plants via symbiosis with microorganisms. Environmental Microbiology Reports 2: 500-506.

Rosenberg E, Zilber-Rosenberg I. 2018. The hologenome concept of evolution after 10 years. Microbiome 6: 78.

Roughgarden J. 2019. Holobiont evolution: model with vertical vs. horizontal microbiome transmission. bioRxiv: 465310.

Rubin-Blum M, Antony CP, Sayavedra L, et al. 2019. Fueled by methane: deep-sea sponges from asphalt seeps gain their nutrition from methane-oxidizing symbionts. ISME Journal 13: 12091225.

Saha M, Berdalet E, Carotenuto Y, et al. 2019. Using chemical language to shape future marine health. Frontiers in Ecology and the Environment 17: 530-537.

Saha M, Weinberger F. 2019. Microbial "gardening" by a seaweed holobiont: Surface metabolites attract protective and deter pathogenic epibacterial settlement. Journal of Ecology 107: 22552265.

De Schryver P, Vadstein O. 2014. Ecological theory as a foundation to control pathogenic invasion in aquaculture. ISME Journal 8: 2360-2368.

Segev E, Wyche TP, Kim KH, et al. 2016. Dynamic metabolic exchange governs a marine algalbacterial interaction. elife 5 .

Selosse M-A, Bessis A, Pozo MJ. 2014. Microbial priming of plant and animal immunity: symbionts as developmental signals. Trends in Microbiology 22: 607-613.

Seyedsayamdost MR, Case RJ, Kolter R, Clardy J. 2011. The Jekyll-and-Hyde chemistry of Phaeobacter gallaeciensis. Nature Chemistry 3: 331-335.

Seymour JR, Amin SA, Raina J-B, Stocker R. 2017. Zooming in on the phycosphere: the ecological interface for phytoplankton-bacteria relationships. Nature Microbiology 2: 17065.

Shapira M. 2016. Gut microbiotas and host evolution: scaling up symbiosis. Trends in Ecology \& Evolution 31: 539-549.

Shreiner AB, Kao JY, Young VB. 2015. The gut microbiome in health and in disease. Current Opinion in Gastroenterology 31: 69-75.

Singh Y, Ahmad J, Musarrat J, Ehtesham NZ, Hasnain SE. 2013. Emerging importance of holobionts in evolution and in probiotics. Gut Pathogens 5: 12. 


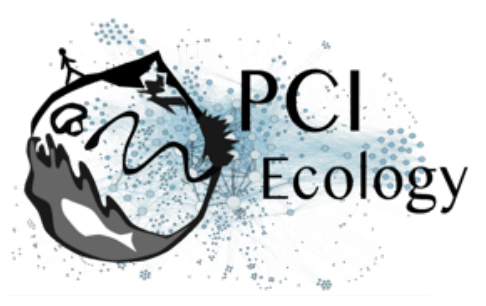

Skillings D. 2016. Holobionts and the ecology of organisms: multi-species communities or integrated individuals? Biology \& Philosophy 31: 875-892.

Smriga S, Sandin SA, Azam F. 2010. Abundance, diversity, and activity of microbial assemblages associated with coral reef fish guts and feces. FEMS Microbiology Ecology 73: 31-42.

Spoerner M, Wichard T, Bachhuber T, Stratmann J, Oertel W. 2012. Growth and thallus morphogenesis of Ulva mutabilis (Chlorophyta) depends on a combination of two bacterial species excreting regulatory factors. Journal of Phycology 48: 1433-1447.

Stegen JC, Lin X, Fredrickson JK, et al. 2013. Quantifying community assembly processes and identifying features that impose them. The ISME Journal 7: 2069-2079.

Theis KR. 2018. Hologenomics: systems-level host biology. mSystems 3: e00164-17.

Thompson AW, Foster RA, Krupke A, et al. 2012. Unicellular cyanobacterium symbiotic with a single-celled eukaryotic alga. Science 337: 1546-1550.

Thompson LR, Sanders JG, McDonald D, et al. 2017. A communal catalogue reveals Earth's multiscale microbial diversity. Nature 551: 457.

Tolstoy LN. 1878. Анна Каренина. Moscow: Русский вестник.

Troussellier M, Escalas A, Bouvier T, Mouillot D. 2017. Sustaining rare marine microorganisms: Macroorganisms as repositories and dispersal agents of microbial diversity. Frontiers in Microbiology 8: 947.

Vallet M, Strittmatter M, Murúa $P$, et al. 2018. Chemically-mediated interactions between macroalgae, their fungal endophytes, and protistan pathogens. Frontiers in Microbiology 9: 3161.

de Vargas C, Audic S, Henry N, et al. 2015. Eukaryotic plankton diversity in the sunlit ocean. Science 348: 1261605.

Venn AA, Loram JE, Douglas AE. 2008. Photosynthetic symbioses in animals. Journal of Experimental Botany 59: 1069-80.

de Vienne DM, Refrégier G, López-Villavicencio M, Tellier A, Hood ME, Giraud T. 2013. Cospeciation vs host-shift speciation: methods for testing, evidence from natural associations and relation to coevolution. New Phytologist 198: 347-385.

Wallin IE. 1925. On the nature of mitochondria. IX. Demonstration of the bacterial nature of mitochondria. American Journal of Anatomy 36: 131-149.

Webster NS, Taylor MW, Behnam F, et al. 2010. Deep sequencing reveals exceptional diversity and modes of transmission for bacterial sponge symbionts. Environmental Microbiology 12: 207082.

Wichard T. 2015. Exploring bacteria-induced growth and morphogenesis in the green macroalga order Ulvales (Chlorophyta). Frontiers in Plant Science 6: 86.

Wichard T, Beemelmanns C. 2018. Role of chemical mediators in aquatic interactions across the prokaryote-eukaryote boundary. Journal of Chemical Ecology 44: 1008-1021.

Williams SCP. 2014. Gnotobiotics. Proceedings of the National Academy of Sciences of the United States of America 111: 1661.

Wiltshire KH, Kraberg A, Bartsch I, et al. 2010. Helgoland Roads, North Sea: 45 years of change. Estuaries and Coasts 33: 295-310.

Wolfowicz I, Baumgarten S, Voss PA, et al. 2016. Aiptasia sp. larvae as a model to reveal mechanisms of symbiont selection in cnidarians. Scientific Reports 6: 32366.

Zaneveld JR, McMinds R, Vega Thurber R. 2017. Stress and stability: applying the Anna Karenina principle to animal microbiomes. Nature Microbiology 2: 17121.

Zengler K, Palsson BO. 2012. A road map for the development of community systems (CoSy) 


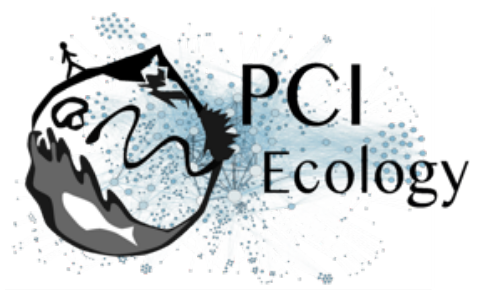

biology. Nature Reviews Microbiology 10: 366-372.

Zilber-Rosenberg I, Rosenberg E. 2008. Role of microorganisms in the evolution of animals and plants: the hologenome theory of evolution. FEMS Microbiology Reviews 32: 723-35. 